"Mircea cel Batran" Naval Academy Scientific Bulletin, Volume XX - 2017 - Issue 1

The journal is indexed in: PROQUEST / DOAJ / Crossref / EBSCOhost / INDEX COPERNICUS / DRJI / OAJI I

JOURNAL INDEX I I2OR / SCIENCE LIBRARY INDEX / Google Scholar / Academic Keys/ ROAD Open Access I

Academic Resources / Scientific Indexing Services / SCIPIO / JIFACTOR

\title{
STUDY ON THE ANALYSIS AND APPLICATION OF INFORMATION OBTAINED THROUGH COMPUTERIZED TECHNOLOGY FOR CORRECTING TYPICAL FAULTS IN THE EXECUTION OF ELEMENT C.105 2/1 Air Turn
}

\author{
Mariana MEZEI ${ }^{1}$ \\ Silvia TEODORESCU ${ }^{2}$ \\ Aura BOTA ${ }^{3}$ \\ ${ }^{1}$ Assistant PhD Politehnica University of Bucharest, ROMANIA \\ ${ }^{2}$ Professor PhD, National University of Physical Education and Sports, Bucharest, ROMANIA, \\ aurabota@ymail.com (corresponding author) \\ ${ }^{3}$ Professor PhD' National University of Physical Education and Sports, Bucharest, ROMANIA
}

\begin{abstract}
In modern training, there is an increased use of computerized workouts based on devices able to capture precise information about the biomechanical parameters of motion or various physiological indicators, in order to shorten the training time and allow a more rigorous control of the variables related to technical execution. Thus, it is implemented an instrumentalization of sports training, which reduces the weight of empirical work in favor of a highly scientific one. Technological transfer to the field of performance sports often creates the difference between top athletes and other competitors.

Computerized training ensures augmentative feedback by providing accurate information (that sometimes is overlooked by the coach) with a prescriptive character, meaning that the athlete knows exactly what to correct at the next repetition. This type of feedback provided by the Xsens Mtw equipment meets some features of the technical elements specific to aerobic gymnastics: the element allows the gymnast to discover relevant sensory information (given that the fast pace of execution or mental tension makes this process difficult); the element is sufficiently complex to require additional information for a top-level execution.
\end{abstract}

Keywords: aerobic gymnastics, computerized training, augmentative feedback.

\section{Introduction}

Performance aerobic gymnastics is a spectacular technical-combinative sport, with complex kinematic elements that exert the athlete's body close to the limit. Competition routines must contain combinations of basic steps and arm movements, all performed to the rhythm of music for creating dynamic, rhythmic and continuous sequences, with changes in the level of execution. Thus, performance is conditioned by a multitude of internal and external factors, among which we highlight sensory afferents as being essential for the knowledge and understanding of external conditions or the athlete's body condition at a given moment. This sensory information, known as feedback in the specialized language, is directly related to the performed movements and relies on the athlete's sensations and perceptions. The feedback model based on performance knowledge [1] is suitable for the situations where the coach is interested in correcting inaccurate movements rather than reaching a specific result (score). Also, feedback helps identify some technical issues difficult to perceive by the athlete - for example, the direction of action of a segment or changing it, at a given moment, into a complex movement
Some research studies [2,3] suggest quite clearly that the efficiency of kinematic feedback depends on the nature of the task to be performed; if it contains hardly accessible and cognoscible zones, then the benefits of augmentative kinematic feedback are optimized. The same applies to improve technical difficulty elements, whose multiple spatial and temporal parameters found under the incidence of a high execution speed cannot always be fully realized and controlled by the athlete ( $1 / 2$ Turn Tuck Jump $1 / 2$ Twist to 1 Arm Push Up, 1/1 Turn Pike Jump 1/2 Twist to Push Up, 1/1 Turn Split Jump to Split Drawing). The aforementioned authors argue the importance of knowing the task to be performed and the sources of feedback in a relevant study for the topic of this paper, due to its specificity. The purpose of the experiment consisted in the execution of a bilateral coordination task, where the action of upper limbs was different; the left limb had to perform a flexion movement in the elbow joint, and the right limb, a flexion-extensionflexion movement at the same level. In the absence of practice, this task is quite difficult to accomplish, because there is a tendency to perform the same movements with both segments symmetrically. Swinnen (1993) asserts that the ability to execute correctly the different tasks of 


\section{"Mircea cel Batran" Naval Academy Scientific Bulletin, Volume XX - 2017 - Issue 1 \\ The journal is indexed in: PROQUEST / DOAJ / Crossref / EBSCOhost / INDEX COPERNICUS / DRJI / OAJI / JOURNAL INDEX I I2OR / SCIENCE LIBRARY INDEX / Google Scholar / Academic Keys/ ROAD Open Access I Academic Resources / Scientific Indexing Services / SCIPIO / JIFACTOR}

both segments has recorded little progress in the absence of augmentative feedback, which, once provided, enabled the subjects to find new strategies for the decoupled learning of tasks. This type of approach is also interesting for aerobic gymnastics, where asymmetric movements are performed at different speeds in the upper body, while the lower body performs actions that require a different pattern of neuromuscular activation.

The analysis of intrinsic feedback, which is related to the motor task perceived by the subject, or extrinsic feedback, additional to the task, shows that both are relevant for a successful task/technical element, provided that the athlete is able to become aware, select and process the needed information [4], which determines the success, in terms of execution.

The nature of the available information varies depending on the moment when feedback occurs; for instance, in gymnastics, the feed-before contains data about the positions and movements of segments in different axes and planes during the three phases of the element, information relating to either the characteristics of the podium, which requires different "loading" when losing contact with the ground, or the optimal duration/speed of execution.

\section{Organizing and conducting the research}

The research was organized and conducted during the precompetitive period of athletes in the national aerobic gymnastics team, and aimed to increase training state and improve technical preparation, with an emphasis on the connections of higher difficulty elements included in the competition routines.

\section{Hypothesis \\ Using the auditory feedback provided by CASIONOR methodology leads to shortening the correction time and improving technical execution.}

\section{Research methods used}

Study of literature, observation method, methods and means for the kinematic objectification of difficulty elements and their correction, experiment method, statistical and mathematical method

\section{Subjects}

Six athletes, members of the Romanian national team, with over 8 years of experience in practicing aerobic gymnastics, who show imperfections in the execution of technical elements from group $\mathrm{C}$. The gymnasts' level of technical and artistic preparation is relatively heterogeneous, which is due, on the one hand, to their different competitive experience and, on the other hand, to their native abilities.
Concurrent feedback (which occurs while performing the element), although less common due to the short durations of element execution, can relate to the awareness and rapid correction by the athlete of some positions or angles during flight and to the adoption of a correct position in the preparation for landing.

Feedback, after achieving the technical element, refers to the set of sensations and perceptions felt by the athlete during execution, which can be expressed, analyzed and compared in the discussions with their coach or teammates. This is the moment when the coach makes judgments about technical correctness, emphasizing the ideal motor sensations associated to it, or provides information about the identified execution faults. Augmentative feedback can also be verbal, when the score is displayed after a gymnastics routine.

Without minimizing the essential role of feedback in sports training, it should be noted that the abuse of information from the coach, without a careful selection of the amount and time to administer it, may lead to disorganization of the athlete's behavior or, even worse, to the creation of dependency, which cancels their awareness and responsibility-taking in relation to their performance in training and competitions [5].

Athletes followed a correction program based on the prosthetic information methodology, as a complementary means of technical preparation.

A correction framework-program using the computerized system with real-time feedback In order to achieve complementary training for correcting typical faults, athletes followed a program that included the execution of two elements from group C within 6 lessons conducted during 6 consecutive days.

In the first 2 days, gymnasts executed a total of 50 repetitions in 5 series of 5 repetitions each with low-impact step and 5 series of 5 repetitions each with assemblé.

The breaks between series lasted about 10 minutes. Starting with the third day, the number of repetitions per series increased, reaching an average of 10 , and the number of series decreased to 4. Technical executions were monitored and, depending on deviations from the ideal movement pattern, a sound stimulus was signaling the athlete that the technical element contained a typical fault, meaning the deviation of feet from zero point.

Dosing the amount of repetitions had as an argument, on the one hand, the awareness of kinesthetic sensations in the lower body, and on the other hand, the development of specific 
"Mircea cel Batran" Naval Academy Scientific Bulletin, Volume XX - 2017 - Issue 1

The journal is indexed in: PROQUEST / DOAJ / Crossref / EBSCOhost / INDEX COPERNICUS / DRJI / OAJI I JOURNAL INDEX I I2OR / SCIENCE LIBRARY INDEX / Google Scholar / Academic Keys/ ROAD Open Access I Academic Resources / Scientific Indexing Services / SCIPIO / JIFACTOR

endurance, given that these elements can be performed at the end of competition routines, when physical and mental fatigue becomes prominent.

Biomechanically speaking, the focus was on the entry to element and the position of feet when pushing off the ground to jump. In this regard, it was accepted, in the first training day, a deviation of $30^{\circ}$, and then the deviation was reduced to $20^{\circ}$, $15^{\circ}$ and $12^{\circ}$, a value considered acceptable for the visual acuity of the jury, which demonstrates a specialized sense and different motor control according to these ones.
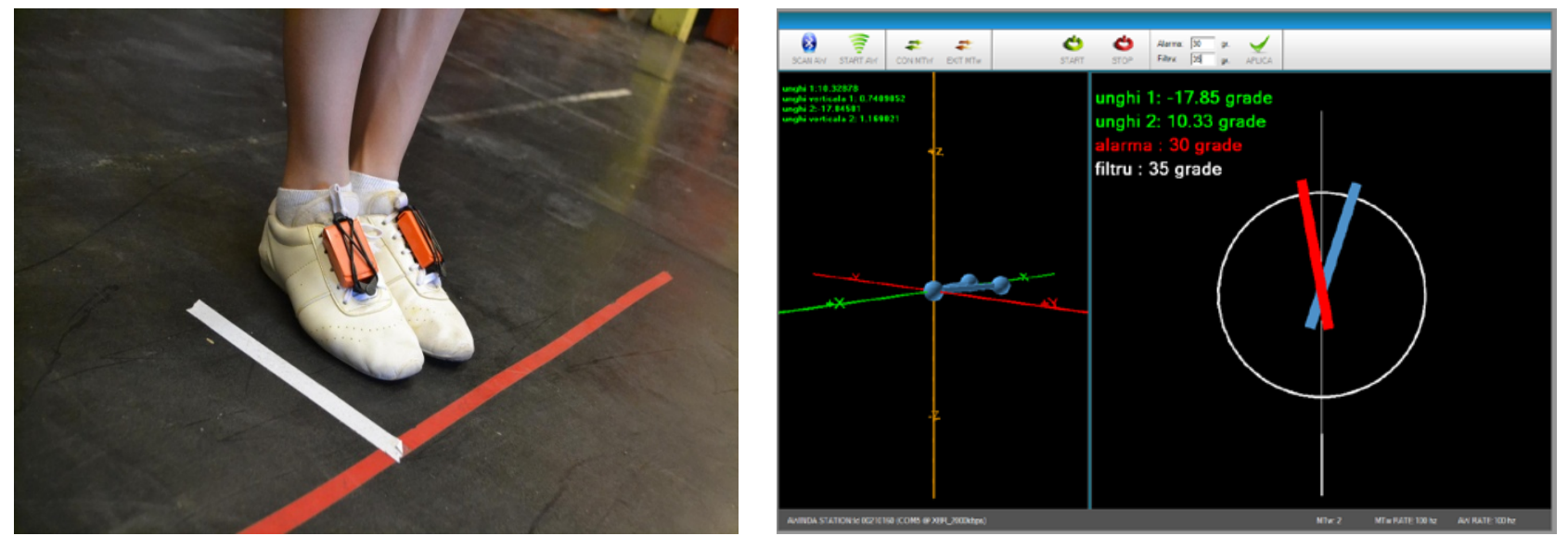

Fig. 1.Screen capture for an execution with a 30-degree tolerance

This type of computerized training also provides data on the optimum entry to element, each gymnast showing a predilection for the step or assemblé momentum. The series of repetitions have revealed various faults in the two types of momentum, which demonstrates a specialized sense and different motor control for each of them.

\section{Analysis and interpretation of results}

To highlight the evolution of angular values that describe the performed movement, there are presented below, in a graphical form, the values for the five executions as initial tests (TI) and the values for the five executions as final tests (TF). Besides these values showing the foot rotation around the vertical Z-axis (local reference), there are also presented the average values regarding the foot rotation around $\mathrm{Y}$-axis, so that, within the analysis, one can discern between an internal or external foot rotation, an aspect penalized in the competition, and a rotation performed with the foot in plantar flexion.

As can be seen in Fig. 2, the positioning of inertial navigation units provides information on the foot kinematics in the local reference system, which makes plantar flexion to change rotational axes. Thus, Z-axis of the foot goes very close to the vertical X-axis of lower leg.

This situation requires presenting in the graphs the evolution of plantar flexion/dorsal flexion of the foot (rotation around $\mathrm{Y}$-axis in the local reference system). 
"Mircea cel Batran" Naval Academy Scientific Bulletin, Volume XX - 2017 - Issue 1

The journal is indexed in: PROQUEST / DOAJ / Crossref / EBSCOhost / INDEX COPERNICUS / DRJI / OAJI / JOURNAL INDEX I I2OR / SCIENCE LIBRARY INDEX / Google Scholar / Academic Keys/ ROAD Open Access I Academic Resources / Scientific Indexing Services / SCIPIO / JIFACTOR

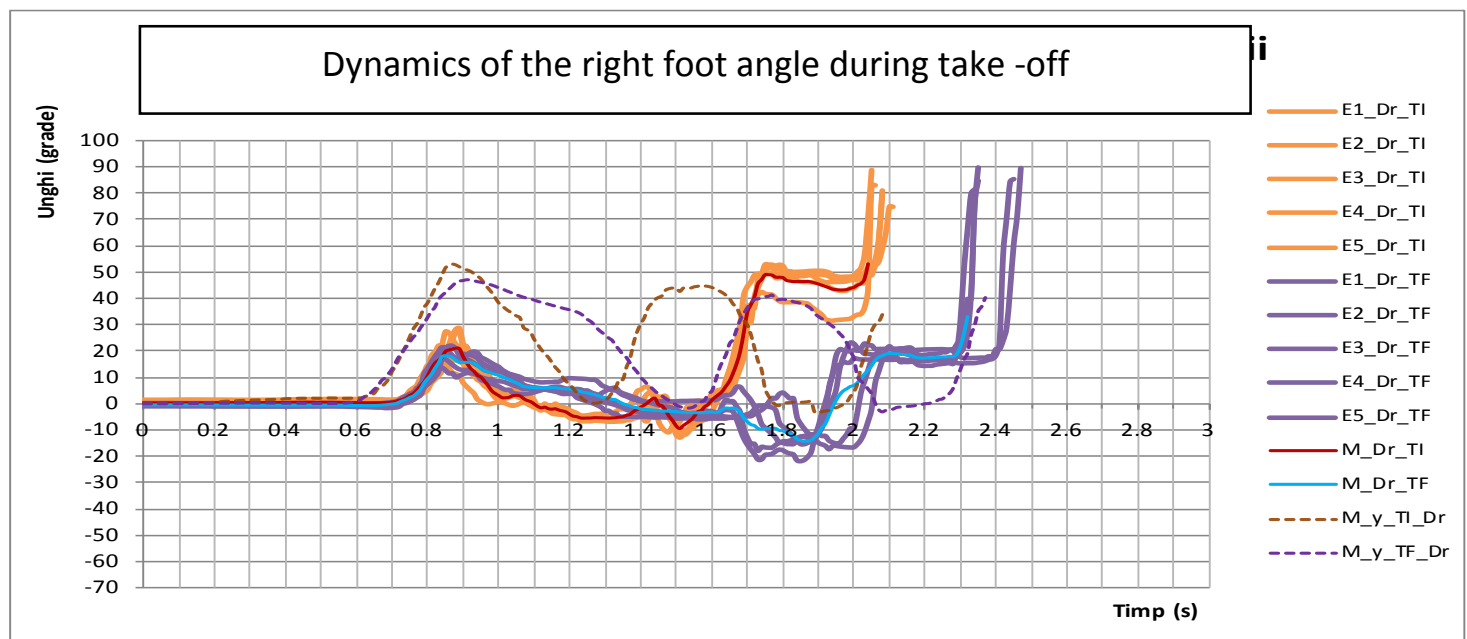

Fig.2. Athlete O.A. - Initial testing vs. Final testing, Air Turn - right foot

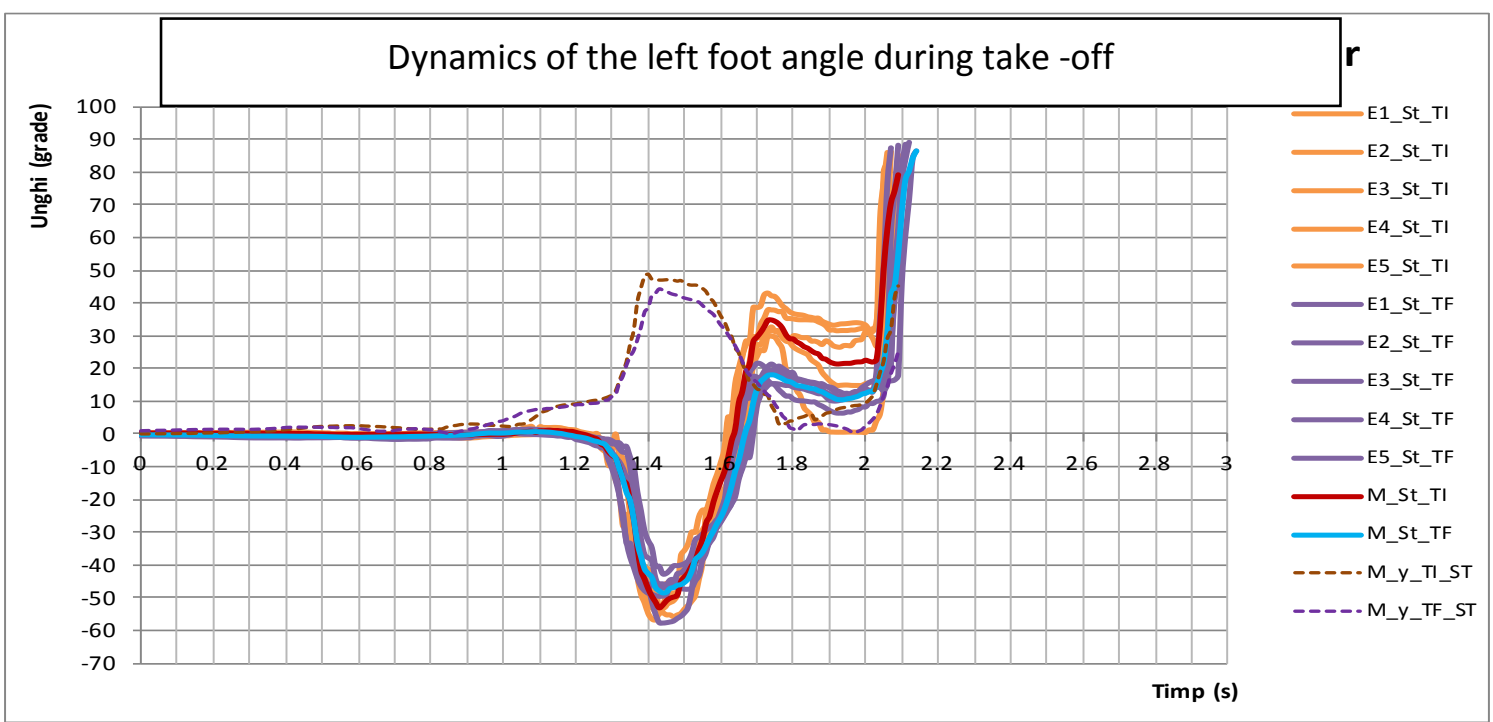

Fig.3. Athlete O.A. - Initial testing vs. Final testing, Air Turn - left foot

Subject O.A.- C.105 2/1 Air Turn - right foot: in the initial testing, a deviation occurs because of a 50-degree outward rotation of the foot, compared to 20 degrees after completing the computerized training program; final correction is 30 degrees. The same data collected during the two tests emphasize a longer duration in the final testing as regards the step execution with the right foot, which suggests greater attention paid to the correctness of execution.

Subject O.A. -C.105 2/1 Air Turn -left foot: it can be noted a strong foot rotation to the left, but according to average values of the foot rotation around $\mathrm{Y}$-axis, it is found that it executes a plantar flexion, and thus the foot rotation to the left is performed in another plane than the horizontal one.
As to the left foot position in the horizontal plane after regaining contact with the ground, one can see, in the initial testing values, an increased variation in value of the deviation angle compared to final testing, where this variation is reduced.

As in the case of right foot, it is found a correction of execution with an angular value of at least 10 degrees.

Following the computerized training, it has been noted: a 30-degree correction for the right foot; a10-degree correction for the left foot; longer execution time with the right foot by $0.4 \mathrm{sec}$. and the same execution time with the left foot.

Results obtained from this experimental study have confirmed the idea according to which the prosthetic information methodology can be successfully used in high-performance aerobic gymnastics. 


\section{"Mircea cel Batran" Naval Academy Scientific Bulletin, Volume XX - 2017 - Issue 1 The journal is indexed in: PROQUEST / DOAJ / Crossref / EBSCOhost / INDEX COPERNICUS / DRJI / OAJI / JOURNAL INDEX I I2OR / SCIENCE LIBRARY INDEX / Google Scholar / Academic Keys/ ROAD Open Access I Academic Resources / Scientific Indexing Services / SCIPIO / JIFACTOR}

\section{Conclusions}

Computerized training, intensively used for a week, provided solutions on the correction of some defective movement stereotypes mostly encountered in the momentum and vertical take-off phases for C.105, by using the CASINOR-type methodology.

After processing and interpreting the obtained data modeled in 3D space, regarding the spatial orientation of segments and the take-off angles when the momentum and vertical push off occur, the following conclusions can be drawn:

$\checkmark$ augmentative feedback has led to further awareness of the task to be performed, namely the control of initial position and the way of achieving momentum. Thus, for element C.105, it has been found an improvement in the average value of deviation angle from the starting point (zero position), with values (between $0^{\circ}$ and $30^{\circ}$ ) depending on the motor and cognitive individual characteristics;

$\checkmark$ most subjects showed a high variability of executions in the initial testing, which has gradually decreased through better self-control, also due to intrinsic feedback (auditory stimulus) and extrinsic feedback (result knowledge) provided in real time. Thus, gymnasts showed higher consistency in the series of repetitions performed at the end of the experimental period;

$\checkmark$ an interesting detail objectified in the experiment refers to the fact that, for gymnasts performing the air turn to the right, average deviation of the left foot is higher than that of the right limb, which entails a deviation of the pelvis and shoulder line from the vertical axis in both the momentum and flight phases.

To summarize, one can state that additional external feedback is beneficial to accelerate learning and achieve performance due to internal sources of information. In this context, we can assert that feedback based on performance knowledge leads the subject to focus on internal sources, while feedback based on result knowledge leads the subject to focus on external, environmental sources. Obviously, the prevalence of one afferentation or another is determined by the specificity of each sports branch.

\section{Bibliography}

[1] Bota, A., Mezei, M., Bidiugan, R., (2014), Enhancing technical accuracy in high-level aerobic gymnastics by means of MVN Motion Capture system, The $10^{\text {th }}$ International Scientific Conference eLearning and software for Education Bucharest, April 24-25.

[2] Gentile, A. (1972), A working model of skill acquisition with application to teaching. În Quest, 17, pag 323.

[3] Newell, K., Carlton, M., Antoniou, A. (1990), The interaction of criterion and feed-back information in learning a drawing task, În Journal of motor behavior, 22, pag. 536-552.

[4] Swinnen, S., Walter, C., Lee, T., Serrien, D. (1993), Acquiring bimanual skills. Contrasting forms of information feed-back for interlimb decoupling, În Journal of experimental psychology: Learning, memory and cognition, 19, pag. 1328-1344.

[5] Shams, L., \& Seitz,A., 2008, Benefits of multisensory learning, In Trends in cognitive sciences, vol. XXX.

[6] Mezei, M., (2015), Criterii de eficiență a pregătirii tehnice și artistice în gimnastica aerobică de performanță - Teză de doctorat, UNEFS, București.

[7] Teodorescu, S., (2007), Antrenament și competiție, Editura Moroșan, București.

[8] Dragnea, A., Teodorescu Mate, S., (2002), Teoria sportului, Editura FEST, București. 